\title{
Effect of continuous vs. discontinuous shock on shuttle box avoidance in the rat
}

\author{
K. E. MOYER ANO J. A. CHAPMAN \\ CARNEGIE INSTITUTE OF TECHNOLQGY
}

Discontinuous shock (.2 sec. on and $2.0 \mathrm{sec}$. off) was compared with continuous shock in a shuttle box avoidance situation using rats as subjects. Ss were shown to give a significantly larger number of avoidance responses when discontinuous shock was used as the US.

D'Amato and his associates (D'Amato et al, 1964; Biederman et al, 1964; D'Amato, in press) have repeatedly shown that discontinuous shock is a more effective US than is continuous shock in a discriminated lever press avoidance situation. As D'Amato points out, this finding presents some difficulties for most theoretical accounts of avoidance learning. It therefore seems important to determine whether discontinuous shock is more effective than continuous in other avoidance tasks. This study compares the effects of two types of shock on shuttle box avoidance learning.

\section{Subjects}

Thirty-three naive albino male rats from the Carnegie Tech colony were used. All Ss were 84 to 96 days of age at the beginning of the experiment. The discontinuous shock group had $17 \mathrm{Ss}$, the continuous shock group 16.

\section{Apparatus}

The avoidance box consisted of an alley $20-1 / 2 \mathrm{in}$. long, 11-1/4 in. wide with walls $16-1 / 2$ in. high. The interior of the box was painted gray. The floor consisted of 2 grids of equal size made of $1 / 8 \mathrm{in}$. brass rods spaced $3 / 8$ in. apart on center. They were hinged at the ends and suspended by springs in the center so that the weight of the rat on the grid activated a microswitch. An Applegate stimulator, Model 228, was used to charge the grid. Shock was scrambled with a relay type scrambler (Hoffman \& Fleshler, 1962). The top of the alley was covered with $1 / 8$ in. Plexiglas. A 15 watt bulb was located in the center of each end of the box 11 in. above the grid. Two 4 in. speakers (used alternately) were mounted $7 \mathrm{in}$. behind the center of the box. A masking noise of approximately $69 \mathrm{db}$ was produced by a blower. The CS, a 600 cycle tone, was generated by a Hewlett-Packard sound generator. The CS produced a total sound level of about $83 \mathrm{db}$ as measured inside the avoidance box with a General Radio Company Sound Survey Meter, type 1555A. A control apparatus located in another room automatically timed and presented the events in the avoidance box.

\section{Procedure}

Ss in the two groups were run alternately and differed only in the type of shock. For the discontinuous shock group the shock was on for .2 sec. and off for 2.0 sec. For the continuous shock group, the shock was uninterrupted. The shock level for both groups was 1.5 ma. On the first day of training, the Ss were selected at random from a group cage and placed in a single cage which then became the home cage for the rest of the experiment. Food and water was avallable in the home cage ad lib throughout the entire experiment.

At the beginning of training, the light over the righthand grid was on. The $S$ was placed on the lighted grid facing away from the dark grid. On the first trial, the tone sounded, the light over the right grid went out and at the same time the light on the left grid went on. After a $10 \mathrm{sec}$. interval, the dark grid was charged with a current of $1.5 \mathrm{ma}$. Shock remained on the dark grid until the beginning of the next trial. The tone was terminated as soon as $\mathrm{S}$ ran to the lighted grid. On each subsequent trial, the light shifted, the tone sounded, and the entire grid was free of shock for a $10 \mathrm{sec}$. period followed by shock on the dark grid. The intertrial interval was $15 \mathrm{sec}$. Each $\mathrm{S}$ was given 30 trials per day for 5 days.

An avoidance response was defined as a response of crossing from the dark grid to the lighted one within $10 \mathrm{sec}$. of the presentation of the tone and the changing of the lights. On such a response, s did not receive shock. If $\mathrm{S}$ delayed responding for more than $10 \mathrm{sec}$. it received shock and the response was defined as escape. Spontaneous crossings (i.e., between trials) dropped out quickly because the dark grid was always charged between trials.

\section{Results}

An analysis of variance test on the proportions of avoidance responses in 10-trial blocks showed a difference due to the type of shock stimulus. The mean percentage of avoidance responses for the discontinuous shock group (57.8\%) was greater than for the continuous shock group (36.7\%), $F=7.28, \mathrm{df}=1 / 31, \mathrm{p}<.05$. There was no significant interaction between the type of shock stimulus and blocks of trials.

Figure 1 shows the mean percentage of avoidance responses within 10-trial blocks through the course of learning. The means for the discontinuous shock group are consistently higher than the corresponding means for the continuous shock group.

\section{Discussion}

The results clearly show the superiority of discontinuous over continuous shock in the shuttle-avoidance situation. Whether this superiority will hold when other avoidance procedures are used remains to be 


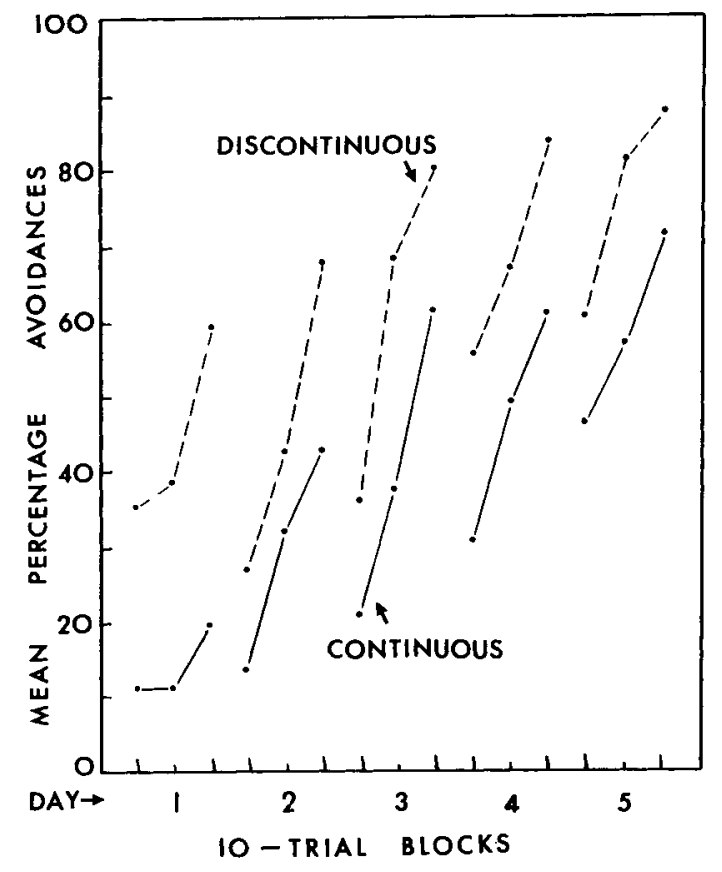

Fig. 1. Mean percentage of avoidance responses plotted in blocks of 10-trials for both the discontinuous shock group $(N=17)$ and the continuous shock group $(\mathrm{N}=16)$.

Continued from page 172.

hypothesis of ECS effects, at least four points should be clarified. First, how do muscular or emotional tensions or their lack produce a competition with performance which simulates the existing interpretation of an inability of ECS treated patients to recall elements of word lists? The supposedly "relaxed" subjects were able to gain sufficient strength to sincerely say, "I don't remember." Second, how is it that extreme emotionality is conditioned so easily to cues outside the apparatus but not to the apparatus itself? Should we postulate yet another gradient of conditioning for these extra-apparatus events? Third, since the statement is made that an ECS study using multiple treatments is not relevant to consolidation theory, further investigation of this moot point is badly needed. Hudspeth, McGaugh, \& Thompson (1964) have found results interpretable as amnesic after several ECS treatments were given to the animals. Lastly, when, if ever, are changes in the CER in any species of animal causally related to avoidance performance?

If these very fundamental questions are answered experimentally, I would acknowledge the existence of a new interpretation of ECS effects (Lewis \& Maher, 1965). Until then, the reader might be interested in another hypothesis (Hudspeth \& Gerbrandt, 1965) consistent with the effects observed in human patients, with phenomenal emotionalities in extra-apparatus seen. Observation of the Ss seems to indicate that the short bursts of shock produced less freezing and fewer perseverative scrambling and bar-biting responses than did the uninterrupted shock. The discontinuous shock did, however, seem to facilitate locomotor responses. Thus, discontinuous shock may facilitate avoidance learning because it moves the required locomotor response up on the Ss response hierarchy and increases the probability that the response will occur and be rewarded. If this is the case, it might be expected that discontinuous shock would be a less effective US in conditioned emotional response (CER) training and in passive avoidance learning when the measured response is one of inactivity.

\section{References}

Biederman, G. G., D'Amato, M. R., \& Keller, D. M. Facilitation of discriminated avoidance learning by dissociation of CS and manipulandum. Psychon. Sci., 1964, 1, 229-230.

D'Amato, M. R. Discriminated lever press avoidance learning as a function of type and intensity of shock. J. comp. physiol. Psychol., in press.

D'Amato, M. R., Keller, D., \& DiCara, L. Facilitation of discriminated avoidance learning by discontinuous shock. $J$. comp. physiol. Psychol, , 1964, 58, 344-349.

Hoffman, H. S., \& Fleshler, M. A relay sequencing device for scrambling grid shock. J. exp. Anal. Behav., 1962, 5, 329-330.

\section{Note}

1. This investigation was supported in part by research grant M-1298 from the National Institute of Health, United States Public Health service. The authors wish to express appreciation to Stephen Eldredge and Wayne Adams who served as research technicians on this project.

situation, with dissociations between CER effects and avoidance performance, and with neuroanatomical functions related to ECS effects.

\section{References}

Gerbrandt, L. K., \& Thomson, C. W. Competing response and amnesic effects of electroconvulsive shock under extinction and incentive shifts. J. comp. physiol. Psychol., 1964, 58, 208-211.

Hudspeth, W, J., McGaugh, J. L., \& Thomson, C. W. The aversive and amnesic effects of electroconvulsive shock. $J$. comp. physiol. Psychol., 1964, 57, 61-64.

Hudspeth, W. J., \& Gerbrandt, L. K. Electroconvulsive shock: conflict, competition, consolidation, and neuroanatomical functions. Psychol. Bull., 1965, 63, 377-383.

Kamin, L. J., Brimer, C. J., \& Black, A. H. Conditioned suppression as a monitor of fear of the $C S$ in the course of avoidance training. $J$, comp. physiol. Psychol., 1963, 56, 497-501.

Kast, E., \& Zweibel, A. Changes in bloodclotting time and bloodsugar levels in relation to electroshock therapy. Psychosom. Med., 1954, 16, 334-339.

Lewis, D. J., \& Maher, B. A. Neural consolidation and electroconvulsive shock. Psychol. Rev., 1965, 72, 225-239.

Mikulus, W. L., \& Isaacson, R. L. Impairment in perseveration in delayed tasks due to bilateral lesions of the caudate nucleus in rats, Psychon. Sci., 1965, 3, 485-486.

Thompson, R., Lesse, HI, \& Rich, Irene. Dissociation of visual and auditory habits following pretectal lesions in rats and cats. J. comp. Neurol., 1963, 121, 161-172.

Williams, G. J. The effect of electroconvulsive shock on an instrumental conditioned emotional response ("conflict"). J. comp. physiol. Psychol., 1961, 54,633-637.

Williams, M. Memory studies in electric convulsive therapy. $J$. Neurol. Neurosurg. Psychiat., 1950, 13, 30-35. 